\title{
A New Conference Journal, Proceedings
}

\author{
Proceedings Editorial Office
}

MDPI AG, St. Alban-Anlage 66, 4052 Basel, Switzerland; proceedings@mdpi.com

Published: 13 April 2017

Academic communication takes many forms. Some is very informal, such as conversations with colleagues or social media posts, and others are more formal, such as theses and journal publication. In between is a whole range of other modes of communication, perhaps typified by the academic conference. In some ways it is very informal: a coming-together of like-minded people to discuss the latest research. Even work presented in the main sessions may be tentative, and valuable feedback and discussion can be had over coffee or dinner. On the other hand, they offer an excellent venue for the announcement of the latest innovations, and acceptance of new ideas at a conference can be an important initial test: these aspects of conferences are more formal and are often recorded and shared.

Since the advent of the Internet, new opportunities for communication in every sphere have become possible. This is no less the case in academia, although it has sometimes been accused of being relatively conservative in its adoption of new methods of communication. MDPI has been running online-only conferences since 1997 [1], in addition to physical conferences.

With all these changes and the rapid increase in knowledge, two aspects are becoming increasingly important:

(1) Long-term, systematic archiving of records.

(2) Discoverability of published content.

For these reasons, we have decided to start the journal Proceedings to support the formal archiving of all kinds of conference records. All items published will receive a digital object identifier and we aim for them to be available through various indexing channels that readers frequently use to source new information. Proceedings will publish different kinds of content, including abstracts, posters, full papers, conference reports and so on, to give the opportunity to publish as full as possible a record of each meeting covered. We hope it will serve as a valuable reference for conference participants and the wider research community.

\section{Reference}

1. The 1st International Electronic Conference on Synthetic Organic Chemistry, 1-30 November 1997. Available online: http:/ / sciforum.net/conference/ecsoc-1 (accessed on 20 December 2016).

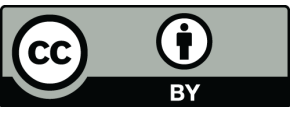

(C) 2017 by the author. Licensee MDPI, Basel, Switzerland. This article is an open access article distributed under the terms and conditions of the Creative Commons Attribution (CC BY) license (http:/ / creativecommons.org/licenses/by/4.0/). 